\title{
Mechanistic force modeling for milling of carbon fiber reinforced polymers with double helix tools
}

\author{
Yiğit Karpat $^{\mathrm{a}, *}$, Naki Polat $(3)^{\mathrm{b}}$ \\ a Department of Industrial Engineering, Bilkent University, Ankara, Turkey \\ ${ }^{\mathrm{b}}$ Turkish Aerospace Industries (TAI), Ankara, Turkey \\ Submitted by Bilgin Kaftanoğlu (1) Atılım University, Ankara, Turkey.
}

\section{A R T I C L E I N F O}

\section{Keywords:}

Machining

Milling

Fiber reinforced plastics

\begin{abstract}
A B S T R A C T
Carbon fiber reinforced polymers (CFRP) have emerged as the material of choice to satisfy increasing demand for lighter aircrafts. Machinability characteristics of CFRPs are quite different than those of metals; therefore, special tool designs have been developed for CFRP machining. The double helix end mill design compresses the upper and lower sides of the laminate using opposite helix angles that eliminate delamination. A mechanistic force model for double helix tools is developed based on milling force data obtained on flat end mills. The proposed model can be used to improve double helix tool designs and to optimize milling process parameters.
\end{abstract}

(C) 2013 CIRP.

\section{Introduction}

Carbon fiber reinforced plastics (CFRP) offer high strength to weight ratio, low thermal expansion coefficient, and high resistance to corrosion. Due to those desirable properties, their usage in new generation of aircrafts has been steadily increasing. CFRP parts are produced near net shape; however, drilling, slot/ side milling, and surface finish milling operations are still required to bring CFRP parts to their final shapes. Machining CFRPs is known to be difficult due to the abrasive nature of carbon fibers and the low thermal conductivity of the material [1]. Diamond coated carbide and polycrystalline diamond tools are usually employed in order to withstand those harsh conditions.

Delamination is the most important issue in machining CFRPs [2]. Machining forces in the axial direction tend to separate the top and bottom layers of the CFRP laminate during machining. Flat end mills with low helix angles are usually used to minimize axial forces. In order to decrease likelihood of delamination and obtain an acceptable level of productivity, milling tools with special designs have been proposed. Double helix tools, also known as right/left helix, minimize axial forces by utilizing two opposite helix angles. As a result, top and bottom layers of the laminate are pushed inwards to decrease the likelihood of delamination.

The number of studies on milling of CFRP laminates is quite limited. Sheikh-Ahmad [3] and Kalla et al. [4] proposed a neural network model based mechanistic force modeling approach for the side milling of CFRP laminates with helical flat end mills. Hintze et al. [5] observed the surface quality during slot milling of uni-directional CFRP laminates. They observed the influence of the fiber direction angle of the top layer on the surface quality. They concluded that maintaining $45^{\circ}$ fiber cutting angle during milling yields the best

\footnotetext{
* Corresponding author.
}

performance. Karpat et al. [6] proposed a fiber direction angle based mechanistic machining model for uni-directional CFRP laminates and showed that it can be extended to calculate milling forces in multi-directional CFRP laminates. Schulze et al. [7] experimentally calculated specific cutting forces on glass fiber reinforced plastics for various levels of process inputs such as cutting velocity, cutting depth, etc. which can be used in tool geometry optimization studies and machining strategy selection.

Despite their common use in industry, no study on double helix tools has been published to the best knowledge of the authors. In order to improve double helix (or similar variations) tool designs and/or to select machining conditions depending on laminate thickness, an experimental investigation is required. In this study, a mechanistic milling force model for double helix tools is proposed and validated through experimental study. Cutting and force coefficients are calculated based on fiber direction of the laminate. Issues related to surface quality and tool wear have also been investigated.

\section{Experimental setup}

A five axis machining center (Dörries Scharmann Technologies, $24 \mathrm{~kW}$ and 24,000 rpm maximum rotational speed) was used in this study during milling of CFRPs. Two different types of CFRP laminates were produced and used in milling experiments. First, uni-directional intermediate modulus laminates consisting of 30 layers with fiber directions of $0^{\circ}$ and $45^{\circ}$ were produced. This laminate allows the investigation of the influence of fiber direction $0^{\circ}, 45^{\circ}, 90^{\circ}$, and $135^{\circ}$ on milling forces. Second, multi-directional CFRP laminates consisting of 72 layers with equal fiber directions repeating with sequence of $0^{\circ} / 45^{\circ} / 90^{\circ} / 135^{\circ}$ were also produced. Mechanical (tensile direction) properties of the intermediate modulus carbon fiber reinforce epoxy resin uni-directional tape are reported in Table 1. 
Table 1

Material properties of CFRP laminates.

\begin{tabular}{llll}
\hline Fiber volume $(\%, \mathrm{v} / \mathrm{v})$ & Strength $(\mathrm{MPa})$ & Modulus $(\mathrm{GPa})$ & Density $\left(\mathrm{g} / \mathrm{cm}^{3}\right)$ \\
\hline 59 & 2690 & 165 & 1.58
\end{tabular}

Two different types of milling tools, both diamond coated carbide tools from the same tool manufacturer, were used in experiments. The first was a helical end mill with a $12 \mathrm{~mm}$ diameter, four teeth and a $10^{\circ}$ helix angle. The second was a double helix end mill with a $10 \mathrm{~mm}$ diameter, has four teeth, and a $20^{\circ}$ helix angle as shown in Fig. 1.
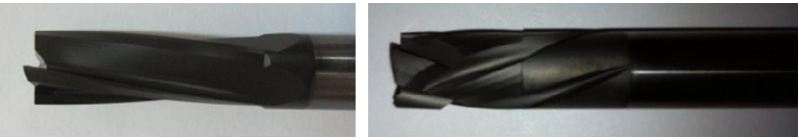

Fig. 1. Diamond coated helical (left) and double helix (right) end mills.

A Kistler 9123 rotating dynamometer and its Kistler 5223 charge amplifier were used to measure milling forces and torque. A sampling rate of $25 \mathrm{kHz}$ was used in measurements.

\section{Milling force modeling for uni-directional CFRP laminates}

During milling operation of uni-directional laminates, the tool tip interacts with different fiber cutting angles $(\beta)$ as the tool rotates. The fiber cutting angle changes depending on the fiber direction of the laminate $(\theta)$ and the tool rotation angle $(\phi)$. The relationship between cutting direction, fiber direction, tool rotation angle, and fiber cutting angle for the slot milling of $0^{\circ}$ fiber direction laminate is shown in Fig. 2. The fiber direction angle $(\theta)$ is measured counterclockwise relative to the tool movement direction.
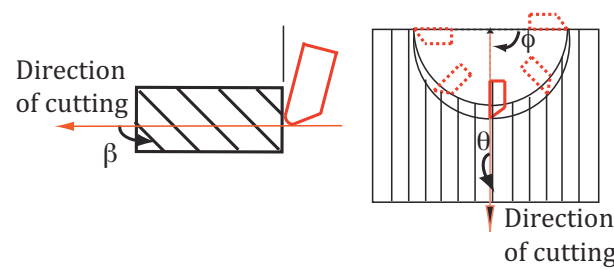

$\theta=0 / 180^{\circ}$

Uni-directional

laminate direction

Fig. 2. Fiber cutting angle $(\beta)$ as a function of tool rotation angle $(\phi)$ and fiber direction of the laminate $(\theta)$.

Mechanistic force modeling approach is a common technique that can be used to calculate milling forces based on material and tool properties. This technique requires some milling tests to be performed to calculate cutting and edge coefficients in radial $\left(K_{r c}\right)$ and tangential $\left(K_{t c}\right)$ directions which represent materials' resistance to machining. Edge coefficients $\left(K_{t e}\right.$ and $\left.K_{r e}\right)$ represent the influence of cutting edge radius and the interaction between the flank face and the work material surface. Cutting and edge coefficients are valid for given tool rake angle $(\alpha)$, clearance angle $(\delta)$, edge radius $\left(r_{e}\right)$, and tool material properties. In the case of milling of uni-directional CFRPs, cutting and edge coefficients vary as a function of fiber cutting angle $(\beta)$. This yields complex functions of cutting and edge coefficients [6] which may not be easily inserted in milling force modeling and machining stability calculations. In this study, cutting and edge coefficients are calculated based on laminate direction $(\theta)$ and average cutting and edge coefficients for the multi-directional CFRP laminate are later calculated based on superposition principle. It must be noted that multi-directional laminates are of practical importance.

Fig. 3 represents cutting forces acting on the tool during the slot milling process where tangential forces $\left(F_{t}\right)$ are directed in the opposite direction of the cutting, and radial forces $\left(F_{r}\right)$ act toward the center of the tool. Eq. (1) represents total cutting forces in tangential and radial directions where $a_{p}$ is the axial depth of cut

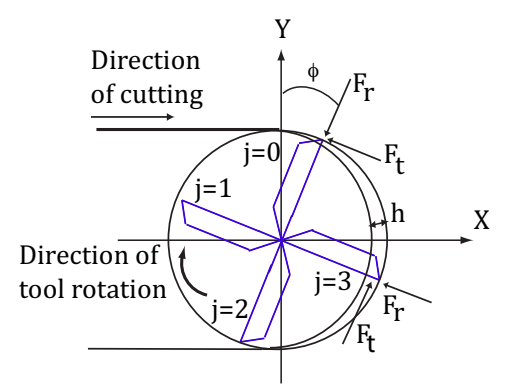

Fig. 3. Milling forces acting on the tool during slot milling.

and $h$ is instantaneous chip thickness which can be calculated, for a circular tool path, by considering feed $(f)$ and tool rotation angle $(\phi)$ as also shown in Eq. (1).

$$
\left[\begin{array}{l}
F_{r} \\
F_{t}
\end{array}\right]=a_{p} \sum_{j=0}^{s-1} g_{j}\left(\left(f \sin \left(\phi_{j}\right)\right)\left[\begin{array}{l}
K_{r c}(\theta) \\
K_{t c}(\theta)
\end{array}\right]+\left[\begin{array}{l}
K_{r e}(\theta) \\
K_{t e}(\theta)
\end{array}\right]\right)
$$

$\phi_{j}=\phi_{0}-j \frac{2 \pi}{s}, \quad j=0,1, \ldots, s-1$

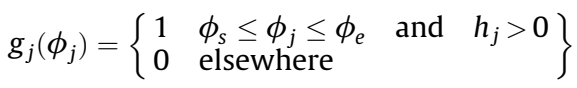

The index $j$ represents the number of teeth on the tool. Depending on the number of teeth on the cutter $(s)$ and the radial depth of cut $\left(a_{e}\right)$, entry $\left(\phi_{s}\right)$ and exit $\left(\phi_{e}\right)$ angles can be calculated. For each tooth on the cutter, instantaneous tool rotation angle is calculated and those teeth which may not be in contact with the material during milling are excluded from force analysis. The tool is sliced in the axial direction, which allows for the influence of the helix angle of the tool. A control function $(g)$ is defined in order to check whether the tool is in the cut or not.

Average tangential force during slot milling can be expressed with Eq. (2), which is integrated over the entry $\left(0^{\circ}\right)$ and exit $\left(180^{\circ}\right)$ angles. A similar expression for radial force can also be written. Average cutting and edge force coefficients as a function of fiber cutting angle can be calculated by using milling force measurements in reverse fashion for a given range of feed values. Milling forces in $x-y$ direction can be calculated through an axis transformation.

$\overline{F_{t}}=\frac{s \cdot a_{p}}{2 \pi} \int_{\phi_{s}}^{\phi_{e}}\left(K_{t c}(\theta) f \sin (\phi)+K_{t e}(\theta)\right) d \phi$

\subsection{Calculation of fiber direction angle based cutting and edge coefficients}

Milling tests at different feed $(0.015-0.02-0.025 \mathrm{~mm} /$ tooth were conducted to calculate cutting and edge coefficients for the helical flat end mill (Fig. 1). Cutting speed (3500 rpm) and axial depth of cut $(3 \mathrm{~mm})$ were kept constant during slot milling experiments. The rotational speed is selected so that the tooth passing frequency is considerably lower than the natural frequency of the rotational dynamometer $\left(w_{n_{-} x}=744 \mathrm{~Hz}\right.$, $w_{n-y}=834 \mathrm{~Hz}$ ). Fig. 4 shows the milling force measurements for each fiber direction with respect to the $x-y$ axis rotating with the dynamometer.

Compared to milling forces in $x$ and $y$ directions, milling forces in $z$-direction $\left(F_{z}\right)$ are very small, which can be attributed to the low helix angle of the end mill. Average milling forces in radial and tangential directions were calculated as a function feed for each fiber direction and are shown in Fig. 5. A linear fit for each data set 


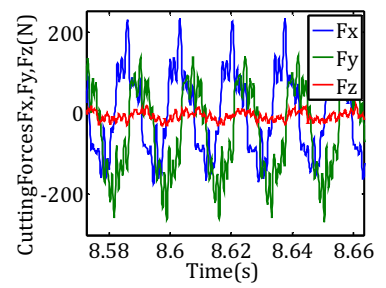

(a)

(c)

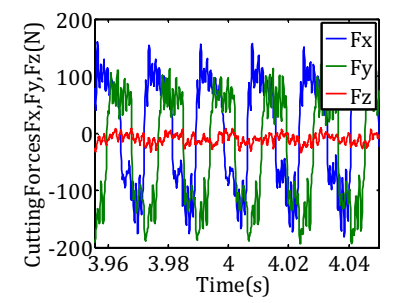

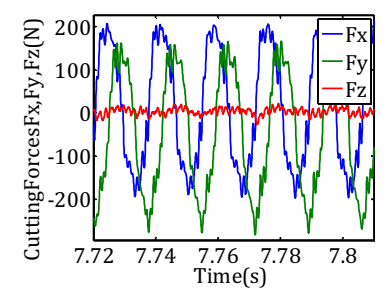

(b)

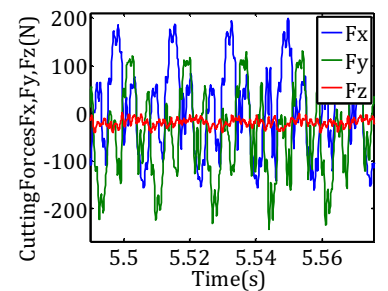

(d)
Fig. 4. Milling force measurements during slot milling. (a) $0^{\circ}$, (b) $135^{\circ}$, (c) $90^{\circ}$, and (d) $45^{\circ}$.

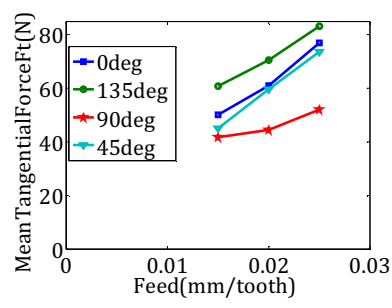

(a)

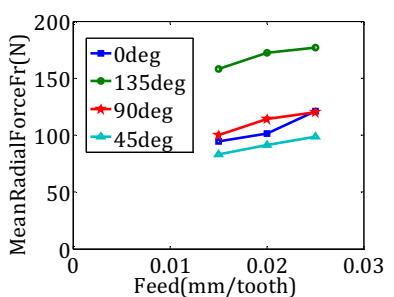

(b)
Fig. 5. (a) Mean tangential and (b) radial forces as functions of feed per tooth.

Table 2

Fiber direction based slope and intercept values and average cutting and edge coefficients.

\begin{tabular}{lllll}
\hline & \multicolumn{3}{c}{$F_{t}$} & \multicolumn{3}{l}{$F_{r}$} \\
\cline { 2 - 4 } \cline { 5 - 5 } & Slope & Intercept & Slope & Intercept \\
\hline $0^{\circ}$ & 2700 & 8.66 & 2640 & 52.8 \\
$135^{\circ}$ & 2237 & 26.7 & 1890 & 131.3 \\
$90^{\circ}$ & 1030 & 25.46 & 2020 & 71 \\
$45^{\circ}$ & 2846 & 2.49 & 1520 & 60 \\
Average & 2203 & 15.8 & 2017 & 78.9 \\
Calculated & $K t_{c}=583 \mathrm{~N} / \mathrm{mm}^{2}$ & $K t_{e}=2.66 \mathrm{~N} / \mathrm{mm} \mathrm{Kr}_{c}=555 \mathrm{~N} / \mathrm{mm}^{2} \mathrm{Kr}_{e}=12.92 \mathrm{~N} / \mathrm{mm}$
\end{tabular}

given in Fig. 5 can be obtained. Table 2 shows the calculated slope and intercept values for each fiber direction.

These cutting and edge coefficients can be used to calculate milling forces in multidirectional CFRP laminates. Radial forces are observed to be significantly larger than tangential forces. It is due to contact between fibers and tool's edge radius and flank face. This shows the importance of edge radius of the tool on machining forces. It must be noted that diamond coating thickness was around $10 \mu \mathrm{m}$ on the tools tested in this study. Although diamond coating protects the tool from wear, it also increases the edge radius, which in turn increase milling forces.

3.2. Cutting force modeling for multi-directional CFRP using double helix milling tools

Fig. 6 shows the unrolled periphery of the double helix cutter, which can be used to visualize the teeth entering and exiting into the cut. The box shows the boundary of milling for slotting operation $\left(\phi=0 \ldots 180^{\circ}\right)$ with a total axial depth of cut given as $a_{p}$. For a tool with four teeth, the spacing between teeth are $45^{\circ}$

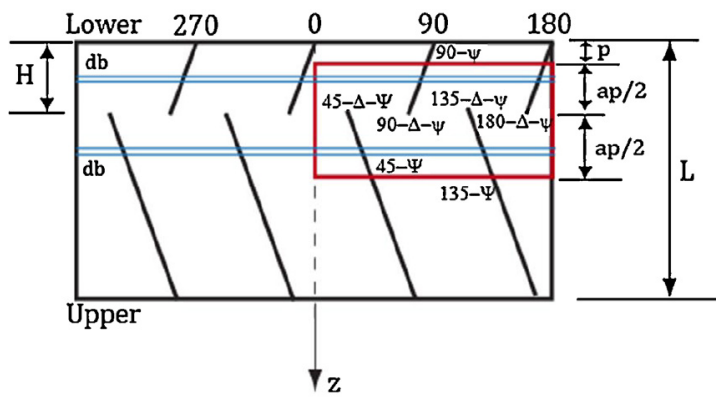

Fig. 6. Schematic of milling with double helix tool.

$(\Omega)$ from the bottom and top of the cutting tool. Due to helix angle and possible small distance $p$, cutting edges enter the cut with a delay $(\Psi)$ and leave the cut with another delay $(\Delta)$. Entry and exit angles for each tooth can be calculated as a function of axial depth of cut $\left(a_{p} / 2\right)$. If the bottom of the tool is aligned with the bottom of the laminate, then $p$ distance and $\Psi$ delay angle become equal to zero. The helix angle, number of teeth $(s)$, height of the bottom helix $(H)$, and the tool diameter $(D)$ are the major tool design parameters.

The tool is then divided into thin slices $(\mathrm{db})$ in the axial direction and each slice is treated as an individual straight tooth end mill, and total cutting forces are calculated by superposing individual forces from each slice in the axial direction.

A double helix milling tool with $5 \mathrm{~mm}$ bottom height $(H)$ is selected to machine a $10 \mathrm{~mm}$ CFRP laminate. In this case, the $p$ distance in Fig. 6 is zero. Special care is given to this issue during regular operation to ensure balance in axial milling forces. If the tool is extended beyond the bottom of the workpiece or a laminate thickness which is not appropriately selected, depending on the tool height, this may result in unbalanced axial machining forces.

\subsection{Validation of the double helix milling tool force modeling}

The above mentioned model is programmed using Matlab software and some validation tests are performed. The calculated average cutting and edge coefficients are used in the mechanistic milling model. Fig. 7 shows the predicted and measured milling forces with respect to reference system rotating with the dynamometer. Since the tool and laminate midpoints are aligned, the milling forces in $z$ direction are not calculated. Since
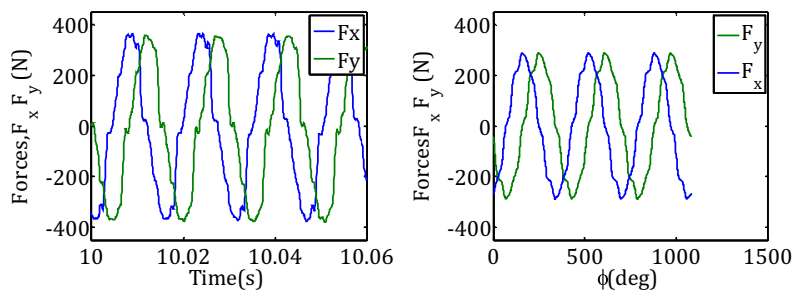

(a)
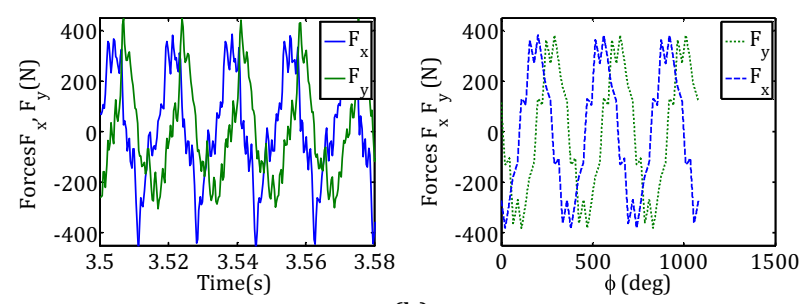

(b)

Fig. 7. Comparison of experimental data (left) and model predictions (right) for two different milling cases: (a) $N=4000 \mathrm{rpm}, f_{r}=254 \mathrm{~mm} / \mathrm{min}, 100 \%$ radial immersion, $a_{p}=10 \mathrm{~mm}$ and (b) $N=3500 \mathrm{rpm}, f_{r}=750 \mathrm{~mm} / \mathrm{min}, 50 \%$ radial immersion downmilling, $a_{p}=10 \mathrm{~mm}$. 
measurements and model predictions are in good agreement, it can be concluded that average cutting and edge coefficients calculated from flat end milling tests can be successfully used to predict double helix milling forces.

It must be noted that the number of teeth on the milling tool can be increased to maintain constant chip thickness throughout milling operation. Fig. 8(a) shows measurements for the case of milling with a six teeth double helix milling tool from the same tool manufacturer. In order to test the model, the tool is extended $2 \mathrm{~mm}$ $(p=2 \mathrm{~mm}$ as shown in Fig. 6 ) beyond the bottom of the laminate. In this case, the lower helix cuts only $3 \mathrm{~mm}$ and the upper helix cuts $7 \mathrm{~mm}$ of the CFRP laminate thickness. Fig. 8(b) shows the milling force prediction obtained from the model. A close agreement between model prediction and measurement was obtained. The influence of not aligning tool and laminate midpoints is reflected on the $F_{z}$ measurements.

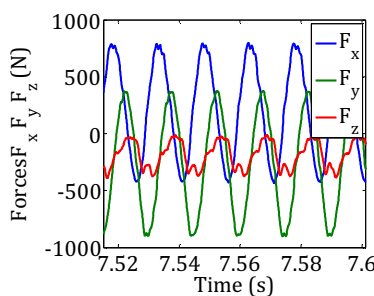

(a)

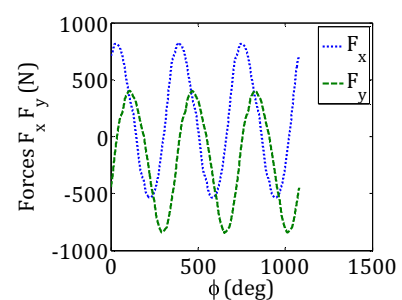

(b)
Fig. 8. Validation of slot milling force predictions for six tooth milling tool: $N=4000 \mathrm{rpm}, f_{r}=1250 \mathrm{~mm} / \mathrm{min}, 100 \%$ radial immersion, $a_{p}=10 \mathrm{~mm}$. (a) Measurement and (b) prediction.

Milling force model proposed here can be extended to investigate issues like surface location error and machining stability [8]. It must be noted that due to low machining speeds and high radial forces, process damping must be taken into account in the analysis. In the next section, the influence of tool wear is investigated.

\section{Influence of machining on diamond coating}

An important consideration in milling of CFRPs is the surface quality, since it affects the assembly conditions of the produced parts. Surface quality is directly related to tool condition. A common issue with diamond coated carbide tools is that their performance significantly deteriorates when the diamond coating is fractured and carbide substrate is exposed. Fig. 9 shows the variation of milling forces and surface roughness as a function of the number of passes (one pass corresponds to $900 \mathrm{~mm}$ of cut). After 17 passes, the magnitude of the milling forces doubles. Fractured diamond coating is also shown in Fig. 9(c) and (d). Surface roughness (Ra) values (measured with Marsurf M300) increased from $2 \mu \mathrm{m}$ to $12 \mu \mathrm{m}$ between first and 17th passes.

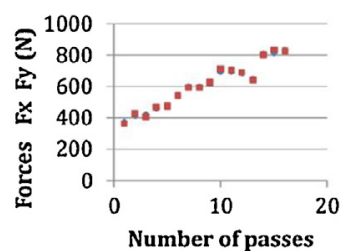

(a)

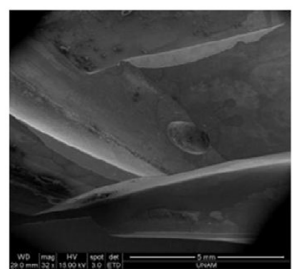

(c)

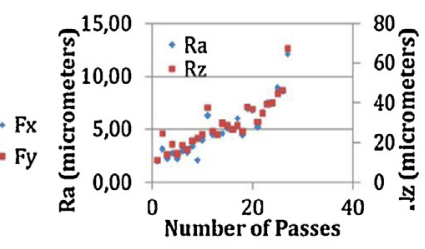

(b)

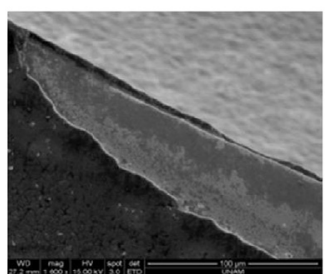

(d)
Fig. 9. (a) Milling force and (b) surface roughness variation due to tool wear as a function of cutting distance $\left(N=4000 \mathrm{rpm}, f_{\mathrm{r}}=254 \mathrm{~mm} / \mathrm{min}, 100 \%\right.$ radial immersion, $a_{p}=10 \mathrm{~mm}$ ). (c and d) SEM images of fractured diamond coating.

\section{Conclusions}

A mechanistic model for milling of multidirectional CFRP laminates using double helix milling tools is proposed. Cutting and edge coefficients are calculated based on the laminate fiber direction. The influence of tool geometry and milling parameters on the process outputs can be investigated by using the proposed model. Due to the abrasive nature of the carbon fibers, edge rounding and fracturing of the diamond coating both influence milling forces.

\section{Acknowledgement}

The authors would like to acknowledge financial support from The Scientific and Technological Research Council of Turkey (Tubitak).

\section{References}

[1] König W, Wulf Ch Graß P, Willerscheid H (1985) Machining of Fibre Reinforced Plastics. CIRP Annals Manufacturing Technology 34(2):537-548.

[2] Teti R (2002) Machining of Composite Materials. CIRP Annals Manufacturing Technology 51:611-634.

[3] Sheikh-Ahmad JY (2009) Machining of Polymer Composites, Springer.

[4] Kalla D, Sheikh-Ahmad J, Twomey J (2010) Prediction of Cutting Forces in Helical End Milling Fiber Reinforced Polymers. International Journal of Machine Tools \& Manufacture 50:882-891.

[5] Hintze W, Hartmann D, Schütte C (2011) Occurrence and Propagation of Delamination During the Machining of Carbon Fibre Reinforced Plastics (CFRPs) - An Experimental Study. Composites Science and Technology 71(15):1719-1726.

[6] Karpat Y, Bahtiyar O, Değer B (2012) Mechanistic Force Modeling for Milling of Unidirectional Carbon Fiber Reinforced Polymer Laminates. International Journal of Machine Tools and Manufacture 56:79-93.

[7] Schulze V, Becke C, Pabst R (2011) Specific Machining Forces and Resultant Force Vectors for Machining of Reinforced Plastics. CIRP Annals Manufacturing Technology 60(1):69-72.

[8] Karpat Y, Bahtiyar O, Değer B (2012) Milling Force Modelling of Multidirectional Carbon Fiber Reinforced Polymer Laminates. Procedia CIRP 1:460-465. 